This item was submitted to Loughborough's Research Repository by the author.

Items in Figshare are protected by copyright, with all rights reserved, unless otherwise indicated.

\title{
Embroidered metamaterial antenna for optimized performance on wearable applications
}

PLEASE CITE THE PUBLISHED VERSION

https://doi.org/10.1002/pssa.201800377

\section{PUBLISHER}

(c) Wiley

\section{VERSION}

AM (Accepted Manuscript)

\section{PUBLISHER STATEMENT}

This is the peer reviewed version of the following article: GIL, I., SEAGER, R.D. and FERNANDEZ-GARCIA, R., 2018. Embroidered metamaterial antenna for optimized performance on wearable applications. Physica Status Solidi (A) Applications and Materials Science, 215 (21), 1800377, which has been published in final form at https://doi.org/10.1002/pssa.201800377. This article may be used for non-commercial purposes in accordance with Wiley Terms and Conditions for Use of Self-Archived Versions.

\section{LICENCE}

CC BY-NC-ND 4.0

\section{REPOSITORY RECORD}

Gil, Ignacio, R.D. Seager, and Raul Fernandez-Garcia. 2019. "Embroidered Metamaterial Antenna for Optimized Performance on Wearable Applications”. figshare. https://hdl.handle.net/2134/35515. 


\section{WILEY-VCH}

DOI: 10.1002/ ((please add manuscript number))

Article type: Communication

\section{Embroidered metamaterial antenna for optimized performance on wearable applications}

\section{Gil*, R. Seager and R. Fernández-García}

Dr. I. Gil, Dr. R. Fernández-García

Department of Electronic Engineering, Universitat Politècnica de Catalunya, Terrassa

(Barcelona) 08222, Spain

E-mail:*ignasi.gil@upc.edu

Dr. R. Seager

Wolfson School of Mechanical, Electrical and Manufacturing Engineering, Loughborough

University, LE11 3TU, United Kingdom

Keywords: Metamaterials, wearable, antennas, wireless body area network

Abstract - In this work, an embroidered metamaterial monopole antenna based on a split ring resonator electromagnetic bandgap shielding structure has been designed, simulated and tested. This work investigates the impact of different types of embroidering metamaterial patterns on the antenna performance, shielding effect in terms of human safety through specific absorption rate analysis and degree of material wearability, in comparison with the standard antenna topologies. The proposed antenna design presents a full compact embroidered metamaterial device manufactured in felt textile substrate and requires a $85 \times 70 \mathrm{~mm}^{2}$ area, operating at 2.45 GHz. On-voxel analysis reveals that specific absorption standards are satisfied for both public and occupational sector with a significant safety margin whereas the antenna performance in terms of gain and directivity are significantly optimized with regard to standard wearable materials.

During the last two decades, research around textile electronics (e-textiles) has allowed the development a technology that enable humans' garments to interact with the technological anthropic surroundings. Indeed, e-garments for wireless body area network (WBAN) applications in sports, fitness, medical/health care and fashion sectors are expected to have a significant market size impact over the next decade [1,2]. To optimize the wireless transceivers, reliable body-worn antennas and systems must be designed and integrated into the e-garments with good wearability and user comfort, considering the most suitable materials and fabrication techniques [3]. Effects such as bending to follow the body morphological curvatures $[4,5]$ and the losses produced by the human tissues at radio frequency range must be taken into account [6]. Moreover, low-profile, lightweight and robust antenna structures must be manufactured by using industrial processes allowing mass production e-garments. The embroidery process is an 


\section{WILEY-VCH}

advantageous technique because of the industrial deployment of digitized embroidered machines [7].

Electromagnetic bandgaps materials (EBGs) have been introduced in many microwave engineering devices in order to efficiently control propagation and radiation. In particular, EBGs and other metamaterials have been applied to wearable antennas to enhance their radiation pattern and increase the isolation with regard to the human body [8-15]. However, those structures present some geometrical drawbacks from the manufacturing point of view: large footprint, protrusion from the body or extra substrate layers such as foam or even air layers, all of which make it difficult to produce a successful wearable garment. EBGs are, indeed, an excellent solution in order to minimize the specific absorption rate (SAR), an established mechanism for measuring the electromagnetic energy absorbed by biological tissue when exposed to radiated electromagnetic energy. In fact, it is required to design the body-worn textile antennas to minimize their impact on human tissues and comply with international SAR regulations.

In this work, an embroidered metamaterial monopole antenna operating at the $2.45 \mathrm{GHz}$ industrial scientific and medical (ISM) radio band is presented. The antenna is manufactured with three felt layers and metallic yarn to obtain a compact wearable implementation. The EBG consists of a $2 \times 2$ matrix of embroidered split ring resonators (SRR). Two different embroidery patterns, satin and contour, have been compared and tested to enhance the antenna performance, and minimize the SAR impact. The proposed antennas have been simulated by means of the commercial full 3D electromagnetic CST Microwave Studio software and tested including the human body impact and SAR using the Voxel human model [16]. The main novelty of our work is to present a fully embroidered structure, including the metamaterial particles themselves, achieving good antenna performance with a higher level of wearability. The experimental section describes the antenna geometry and design. Moreover, the main antenna parameters are evaluated and tested, including the human body impact and the material bending effects. Last, 


\section{WILEY-VCH}

but not least, the SAR on-body analysis for on-voxel model is provided, followed by the main conclusions obtained from this work.

\section{Experimental Section}

Wearable metamaterial antenna design, simulation and test: As a first step, in order to perform realistic simulations, the textile substrate dielectric parameters have been characterized . A split post dielectric resonator (SPDR) was used to determine the dielectric constant and loss tangent of several felt samples by means of the resonance method (Figure 1). The felt relative dielectric constant and loss tangent were measured to be $\varepsilon_{\mathrm{r}}=1.2$ and $\tan \delta=0.0013$. The fabric structure corresponds to a non-woven structure with a $100 \%$ Pes composition. The textile, which is produced by a double-sided needle punching technique has a weight of $211 \mathrm{~g} / \mathrm{m}^{2}$. The scanning electron microscope (SEM) micrograph with the appearance of the felt fabric is shown in Figure 2. The fabric sample used in this work has a thickness of $1 \mathrm{~mm}$.

The unit cell topology of the EBG, consisting of a single SRR over a $1 \mathrm{~mm}$ felt layer and a metallic ground is shown in Figure 3a. It is important to highlight that an intermediate SRR layer is required, because, while the effect of a single ground plane can reduce the backradiaton, it causes significant degradation of the monopole antenna performance. The SRR dimensions are designed in order to achieve a reflection phase of the EBG varying from $180^{\circ}$ to -180 in the vicinity of the resonance frequency of the antenna in order to behave like a perfect magnetic conductor (Figure 3b). The frequency region is restricted to a $90^{\circ} \pm 45^{\circ}$ reflection phase range because this corresponds to the matching frequency band of a wire antenna placed over it, according to the methodology described in [17]. In addition, the suspended line method has been used to confirm the good behaviour of the EBG to suppress surface waves, according to $[18]$.

Initially, the free space design in considered. The proposed metamaterial monopole antenna is shown in Figure 4. A 3-layer felt structure was considered. The first layer includes a basic 


\section{WILEY-VCH}

monopole implemented with Amberstrand Silver 66 yarn consisting of 66 silver coated polymer fibres. The second layer includes a $2 \times 2$ SRR EBG structure as well as the monopole ground layer, both constructed using Amberstrand. Finally, the third layer includes the EBG ground implemented by means of Nora Dell $(0.2 \mathrm{~mm}$ thickness $)$. The total antenna dimensions are $\mathrm{L}=85 \times \mathrm{W}=70 \times \mathrm{t}=3.2 \mathrm{~mm}$. The monopole dimensions are reduced compared to the non-loaded $\lambda / 4$ monopole, because of the slow-wave effect produced by the EBG. Consequently, the output metallic part of the antenna which interacts with the environment is minimized, since the rest of the metallic yarn is sheltered in the intermediate textile layers. The dimensions of the designed antenna are: monopole width/length: $\mathrm{m}_{\mathrm{W}}=3 \mathrm{~mm} / \mathrm{m}_{\mathrm{L}}=28 \mathrm{~mm}$; monopole ground width/length: $\mathrm{m}_{\mathrm{GW}}=70 \mathrm{~mm} / \mathrm{m}_{\mathrm{GL}}=15 \mathrm{~mm} ; \mathrm{SRR}$ width/length: $\mathrm{SRR}_{\mathrm{W}}=\mathrm{SRR}_{\mathrm{L}}=30 \mathrm{~mm} ; \mathrm{SRR}$ metallic width/gap: $\mathrm{SRR}_{\mathrm{M}}=\mathrm{SRR}_{\mathrm{G}}=2 \mathrm{~mm}$; SRR separation to monopole ground: $\mathrm{SRR}_{\mathrm{S}}=1 \mathrm{~mm}$; EBG SRR cell separation: $\mathrm{SRR}_{\mathrm{E}}=5 \mathrm{~mm}$. All the involved metallic layers have been simulated as homogeneous lossy metals to reduce simulation complexity except for the SRR. In that case, since the structures are intended to be embroidered, the performance of two extreme cases have been compared. One is a fully embroidered (homogeneous) SRR and the other uses profile embroidery (minimum embroidery cost). Figure 5 depicts the two cases as well as their return loss simulations. Both topologies show very similar results, with values $|\mathrm{S} 11|<-25 \mathrm{~dB}$. The resonance frequency of the profile embroidery is just detuned $1 \%$ with regard to the operation frequency of the homogeneous case $(2.45 \mathrm{GHz})$. Very similar results can be seen with respect of the antenna radiation pattern. Figure 6 and Figure 7 illustrate the simulated realized radiation pattern for the homogeneous embroidery case. The metamaterial antenna has been compared with the conventional monopole case. The metamaterial antenna realized gain corresponds to $7.81 \mathrm{dBi}$ and exceeds the monopole case by $6 \mathrm{~dB}$. Moreover, the back radiation is reduced by $10 \mathrm{~dB}$ compared to the monopole textile case, demonstrating the effect of the SRR EBG structure. Similar values are obtained for the profile embroidery case. Thus, the 


\section{WILEY-VCH}

embroidery pattern is also effective even in the worst case. All the antenna parameters for free space are summarized in Table 1.

After analyzing the flat case, bending material effects must be considered since wearable antennas usually have to withstand bending stresses while maintaining their radiation performance. Therefore, it is interesting to assess the potential bending impact on the antenna operation frequency. Several bending radii ( $r$ ) have been considered for the bending analysis within the range $40 \mathrm{~mm}<\mathrm{r}<100 \mathrm{~mm}$ with regard to the y-axis (along the monopole axis). Figure 8 shows the proposed antenna return losses under bending. A frequency shift is observed when the bending radius is changed. In particular, for the extreme cases resonant frequencies of $\mathrm{f}=2.48 \mathrm{GHz}$ for $\mathrm{r}=100 \mathrm{~mm}$ and $\mathrm{f}=2.56 \mathrm{GHz}$ for $\mathrm{r}=40 \mathrm{~mm}$ are obtained. Therefore, a shift in the order of $4.5 \%$ must be taken into account with regard to the nominal operation frequency for extreme bending cases.

In order to analyse the impact of the body on the proposed antenna performance, a realistic heterogeneous voxel model has been used in the simulations. In particular, the Gustav male model (38 years old), based on 57 biological tissues (including skin, bones, blood and organs) was used. The metamaterial antenna was located in physical contact with the ear of the voxel model. Figure 9 shows the simulated directivity and realized gain for a conventional monopole felt antenna. It can be observed that there is a significant reduction in the gain $(\mathrm{G}=-2.44 \mathrm{dBi})$ and efficiency $(\eta=13.5 \%)$ due to the impact of the body as a lossy, high dielectric constant medium $(\varepsilon r \approx 40)$. It is observed that the gain and efficiency are improved by using the metamaterial felt antenna (Figure 10). Indeed, for the homogeneous embroidery pattern, the achieved values correspond to $\mathrm{G}=7.19 \mathrm{dBi}$ and $\eta=67.9 \%$. In addition, the profile pattern also involves a good performance: $\mathrm{G}=7.52 \mathrm{dBi}$ and $\eta=70.1 \%$. In fact, the SRR EBG proposed structure behaves like a shaped reflector and, therefore, the directivity is increased in comparison with the free space case. Table 1 summarizes and compares all the obtained antenna parameters. 


\section{WILEY-VCH}

A Brother Entrepreneur ${ }^{\circledR}$ Pro PR1000e embroidery machine was used to manufacture the metamaterial antennas (Figure 11a). The stitch type used corresponds to the ISO 4915:1991 301 standard. In this case, the stitch is formed by a needle thread passing through the material and interlocking with a bobbin thread. Threads meet in the centre of the seam. Stitches appear the same on the top and bottom of the textile. Two stitch types have been implemented. On the one hand, a satin fill pattern (depicted in Figure11b) was used. This pattern is well-suited to narrow columns and shapes and it is selected because it fits the dipole geometry accurately. The stitch spacing corresponds to the distance between two needle penetrations on the same side of a column. For narrow columns, stitches are tight, thus requiring fewer stitches to cover the fabric. In areas with very narrow columns, less dense stitches are required because too many needle penetrations can damage the textile sample. The larger the spacing between stitches, the lower the density. On the other hand, a standard contour fill pattern has been considered (Figure 11c). This embroidery technique consists of a curved fill stitch type following the contours of a shape. It creates a sense of movement in contrast to flatter fills such as satin. The standard contour stitch creates rows of stitches across the dipole shape. The number of stitch lines is constant; therefore, the stitching is denser for narrower antenna geometries. Figure.11d and Figure 11e illustrate the manufactured antennas. The better topology corresponds to the contour pattern, since the yarn distribution is parallel to the induced currents on the SRRs and monopole, thus reducing the overall structure losses. Figure 12 depicts the experimental return loss for the proposed contour embroidered SRR EBG antenna. A good agreement is obtained with regard to the simulations. Due to ohmic losses, there is a lower quality factor in the experimental results with regard to the ideal simulation case. Moreover, the embroidery is not completely homogeneous, as depicted in Figure 11e. This will give rise to some of the increased ohmic losses as well as some very minor variations in line characteristic impedance. It is felt that these variations are small and will not give major error. 


\section{WILEY-VCH}

SAR Analysis: Due to the proximity of the antennas to the human body, SAR is a key parameter to evaluate. There are two maximal SAR values for the general public (head and trunk) and averaging levels depending on the country regulation. On the one hand, the $1.6 \mathrm{~W} / \mathrm{kg}$ averaged over $1 \mathrm{~g}$ tissue, is based on dosimetric considerations and it is considered in USA, Canada and Korea. On the other hand, the $2 \mathrm{~W} / \mathrm{kg}$, averaged over $10 \mathrm{~g}$ tissue, based on biophysical criteria, is applied in the EU, Japan and China [19]. For occupational exposure, those values are increased up to $8 \mathrm{~W} / \mathrm{kg}(1 \mathrm{~g}$ tissue) and $10 \mathrm{~W} / \mathrm{kg}(10 \mathrm{~g}$ tissue). Table 2 summarizes the corresponding exposure limits up to $10 \mathrm{GHz}$ for general public and professional activities. Typically, the mass averaged SAR is computed and compared with the limits of exposure determined by the regulating standards in order to prevent whole body heat stress and excessive local tissue heating. The SAR averaging volume which contains the desired averaging mass tissue is usually calculated by means of the IEEE C95.3 [20] or the IEEE/IEC 62704-1 [21]. In this paper the latter standard has been considered by means of the CST Microwave software. It uses an additional criterion that limits the air volume in valid averaging cubes, improving the performance of the calculation in regions closed to the air. The SAR simulations have been performed over the same model and human head detailed previously, considering a flat antenna on the ear. A reference value of $50 \mathrm{~mW}(17 \mathrm{dBm})$ antenna input power has been considered because it takes into account the typical maximum transmitted power for wearable devices. Figure 13 illustrates the SAR distribution for a conventional monopole felt antenna. Maximum SAR values exceed the public regulation levels due to the omnidirectional radiation pattern of the monopole. In fact, a $53.1 \mathrm{~W} / \mathrm{Kg}(4990 \%$ higher than the limit) for SAR $1 \mathrm{~g}$ tissue and a 15.7 $\mathrm{W} / \mathrm{Kg}(685 \%$ higher than the limit) for SAR $10 \mathrm{~g}$ tissue, are obtained. Those values can be dramatically decreased by means of the proposed SRR EBG structure. Figure 14 shows the SAR 3D distribution for the SRR metamaterial monopole felt antenna. In this case, the SAR regulations are met with a notable safety margin. The reported values for the homogeneous embroidery patterns are $0.64 \mathrm{~W} / \mathrm{Kg}(60 \%$ lower than the limit) for SAR $1 \mathrm{~g}$ tissue and a 0.15 


\section{WILEY-VCH}

$\mathrm{W} / \mathrm{Kg}(92 \%$ lower than the limit) for SAR $10 \mathrm{~g}$ tissue. Moreover, those values are improved for the profile embroidery patterns. In this case SAR $1 \mathrm{~g} / 10 \mathrm{~g}$ values correspond to $0.48 \mathrm{~W} / \mathrm{Kg}(70 \%$ lower than the limit) and $0.12 \mathrm{~W} / \mathrm{Kg}(94 \%$ lower than the limit), respectively. Therefore, a significant shielding effect is achieved due to the SRR EBG since the obtained SAR values are significantly decreased with regard to the conventional layer topology. The maximum allowable input power for the metamaterial shielded antennas has been also considered. The power limits correspond to $21 \mathrm{dBm}$ (homogeneous SRR) / 22.2dBm (profile SRR) for the SAR $1 \mathrm{~g}$ tissue. Table 3 reports all the SAR values and maximum allowed powers.

In conclusion, a novel embroidered metamaterial antenna based on a SRR EBG shielding structure has been presented. The reported simulations and experimental results demonstrate the viability of the antenna in order to optimize the radiation pattern of typical monopole antennas by using a complete body-worn implementation with no air gaps and with a good degree of wearability thanks to the contour embroidery pattern. SAR investigation has been carried out according to the IEEE/IEC 62704-1 standard. The obtained results point out that the proposed material topology complies with the different international regulations applied in the industrialized countries.

\section{Acknowledgements}

This work was supported by the Spanish Ministerio de Educación, Cultura y Deporte under the “Salvador de Madariaga 2017” Program and the Spain-MINECO Project TEC2016-79465-R.

\section{References}

[1] S. Scheneegass and O. Amft, Smart Textiles. Springer, 2017.

[2] Y. Khan, A. E. Ostfeld. C. M. Lochner, A. Pierre and Ana C. Arias, "Monitoring of Vital Signs with Flexible and Wearable Medical Devices”, Adv. Mater., 2016, 28, 4373. 


\section{WILEY-VCH}

[3] W. Zeng, L. Shu, Q. Li, S. Chen, F. Wang, X.-M. Tao, "Fiber - Based Wearable

Electronics: A Review of Materials, Fabrication, Devices, and Applications", Adv. Mat., 2018, 26,5310 .

[4] D. Ferreira, P. Pires, Ruben Rodrigues and R.F.S. Caldeirinha, "Wearable Textile Antennas: Examining the effect of bending on their performance”, IEEE antennas Propag. Mag., 2017, 59, 54.

[5] P. Salonen and Y.R.-Samii, “Textile Antennas: Effects of Antenna Bending on Input Matching and Impedance Bandwidth”, IEEE Aerosp. Electron. Syst. Mag., 2007, 22, 10.

[6] C.C.Y. Poon, B.P.L. Lo, M.R. Yuce, A. Alomainy and Y. Hao, "Body Sensor Networks: In the Era of Big Data and Beyond", IEEE Rev. Biomed. Eng., 2015, 8, 4.

[7] A. Tsolis, W.G. Whittow, A.A. Alexandridis and J.C. Vardaxoglou, "Embroidery and Related Manufacturing Techniques for Wearable Antennas: Challenges and Opportunities”, Electronics, 2014, 3, 314.

[8] A.Y.I. Ashyap, Z.Z. Abidin, S.H. Dahlan, H.A. Majid, S.M. Shah, M.R. Kamarudin and A. Alomainy, "Compact and Low-Profile Textile EBG-Based Antenna for Wearable Medical Applications", IEEE Antennas Wireless Propag. Lett., 2017, 16, 2550.

[9] D. Qu, L. Shafai and A. Foroozesh, "Improving microstrip patch antenna performance using EBG substrates”, IEE Proc. - Microw. Antennas Propag., 2017, 153, 558.

[10] M.A.D. Abbasi, S. Nikolaou, M.A. Antoniades, “A high gain EBG backed monopole for MBAN off-body communication”, Proc. 2016 IEEE International Symposium on Antennas Propag. (APSURSI), 2017, 1907.

[11] J. Tak, Y. Hong and J. Choi, "Textile antenna with EBG structure for body surface wave enhancement", Electronics Lett., 2015, 51, 1131.

[12] J. Vardaxoglou, R. M Edwards, A. Chauraya and S. Bashir, "Compact and Flexible Surfaces Using Electromagnetic Band Gap (EBG)", Proc. of the Fourth European Conference on Antennas Propag., 2014, 1. 


\section{WILEY-VCH}

[13] S. Zhu and R. Langley, "Dual-Band Wearable Textile Antenna on an EBG Substrate", IEEE Trans. Antennas Propag., 2009, 57, 926.

[14] S. Kim, Y.-J. Ren, H. Lee, A. Rida, S. Nikolaou and M.M. Tentzeris, "Monopole antenna with inkjet-printed EBG array on paper substrate for wearable applications", IEEE Antennas Wireless Propag. Lett., 2012, 11, 663.

[15] K. Agarwal, Y.-X. Guo and B. Salam, "Wearable AMC Backed Near-Endfire Antenna for On-Body Communications on Latex Substrate”, IEEE Trans. Compon., Packag., Manuf. Technol., 2016, 6, 346.

[16] https://www.cst.com

[17] F. Yang, Y. R.-Samii, "Reflection Phase Characterizations of the EBG Ground Plane for Low Profile Wire Antenna Applications", IEEE Trans. Antennas Propag., 2003, 51, 2691.

[18] A. Aminian, F. Yang and Y. Rahmat-Samii, "In-phase Reflection and EM Wave Suppression Characteristics of Electromagnetic Band Gap Ground Planes”, IEEE Antennas Propag. Soc. International Symposium, 2003, 430.

[19] H. Mazar, "Human Radio Frequency Exposure Limits: an update of reference levels in Europe USA, Canada, China, Japan and Korea," International Symposium Electromagn. Compat., 2016, pp. 467.

[20] IEEE recommended practice for measurements and computations of radio frequency electromagnetic fields with respect to human exposure to such fields, $100 \mathrm{kHz} 300 \mathrm{GHz}$, IEEE Std C95.3-2002, IEEE-SA Standards Board, 2002, 4, 1.

[21] IEC/IEEE Draft Standard for Determining the Peak Spatial Average Specific Absorption Rate (SAR) in the Human Body from Wireless Communications Devices, $30 \mathrm{MHz}$ - 6 GHz. Part 1: General Requirements for using the Finite Difference Time Domain (FDTD) Method for SAR Calculations, P62704-1/D2, 2013. 


\section{WILEY-VCH}

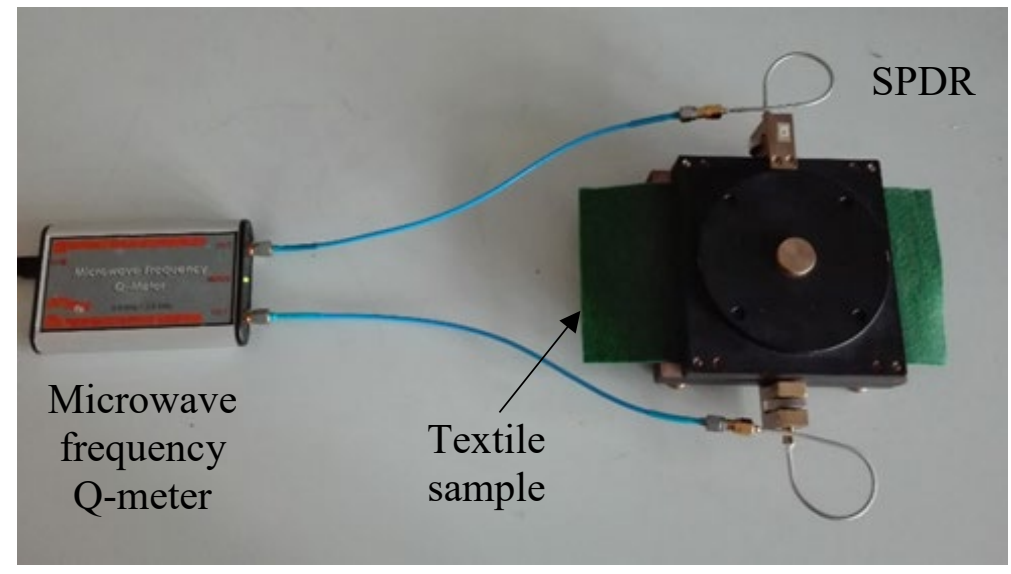

Figure 1. SPDR measurement of the dielectric parameters of the felt fabric. A microwave frequency Q-meter (left side) corresponds to a computer controlled microwave oscillator system. A multipont resonance curve fitting algorithm enables the Q-factor to determine the complex permittivity and loss tangent of the textile sample (right side).

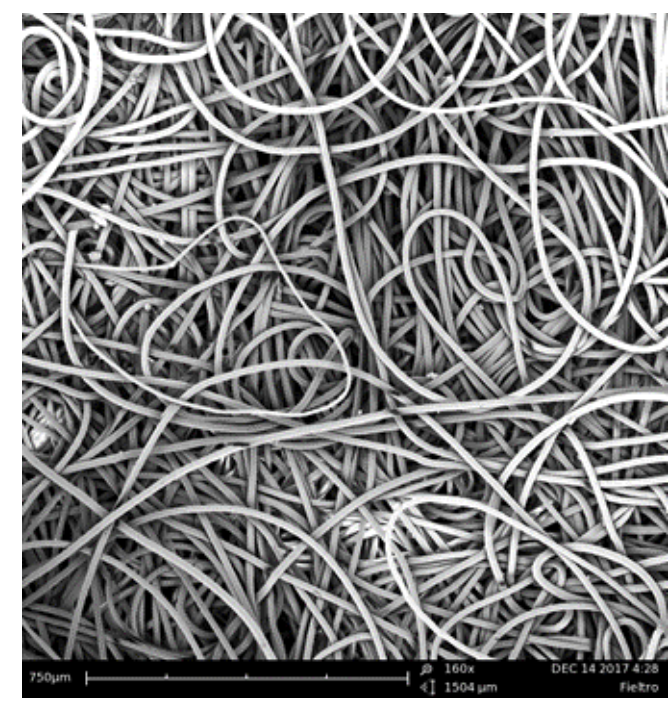

Figure 2. Appearance of the felt textile fabric. SEM micrograph. The sample corresponds to a polyester felt substrate with PES 100\% composition. 


\section{WILEY-VCH}

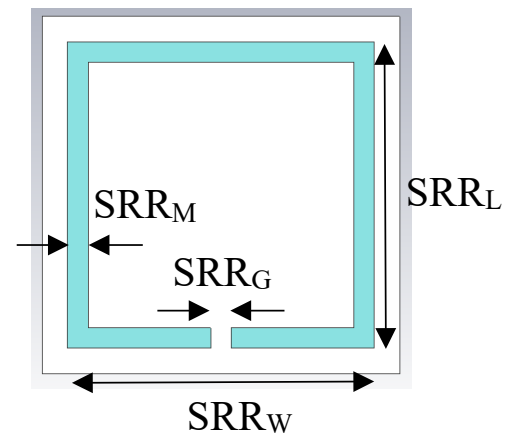

(a)

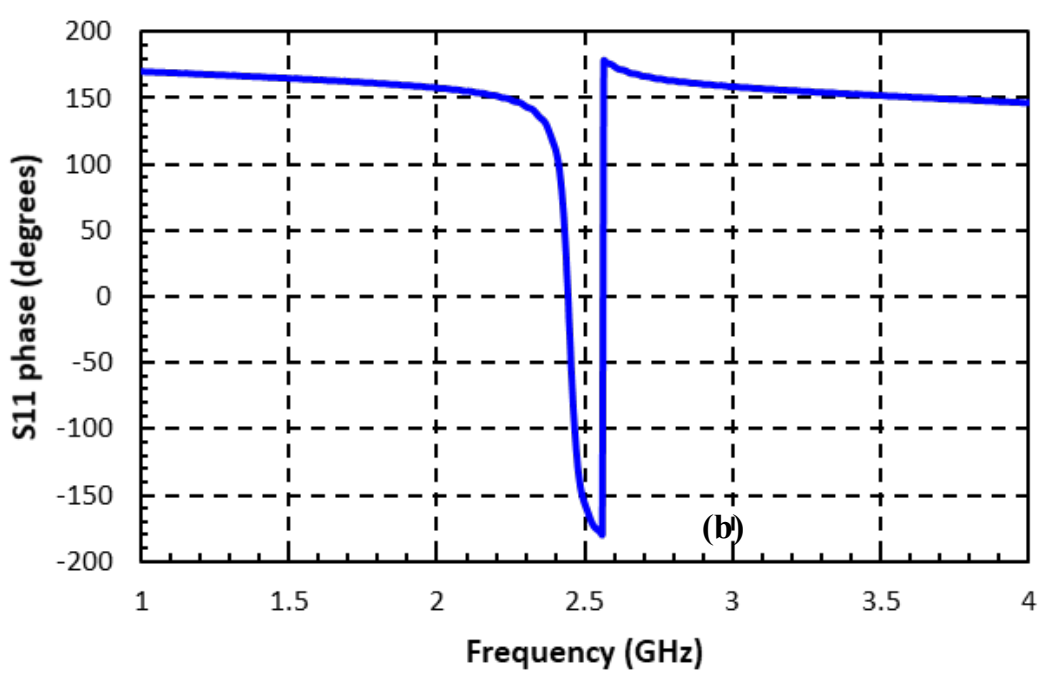

Figure 3. (a) Designed SRR EBG unit cell and geometrical parameters (b) Reflection phase of the EBG surface.

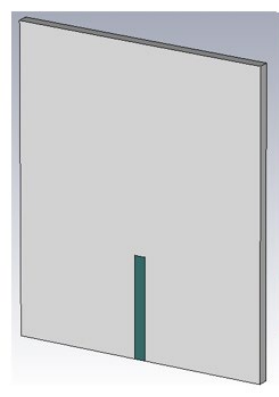

(a)

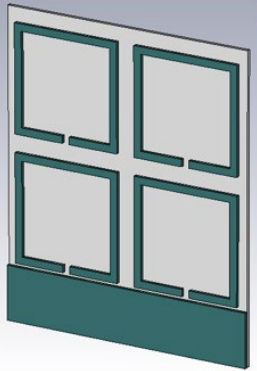

(b)

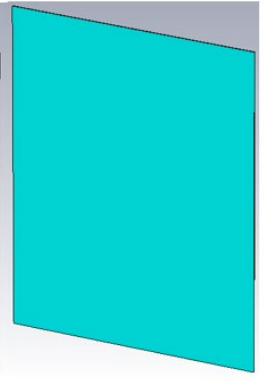

(c)
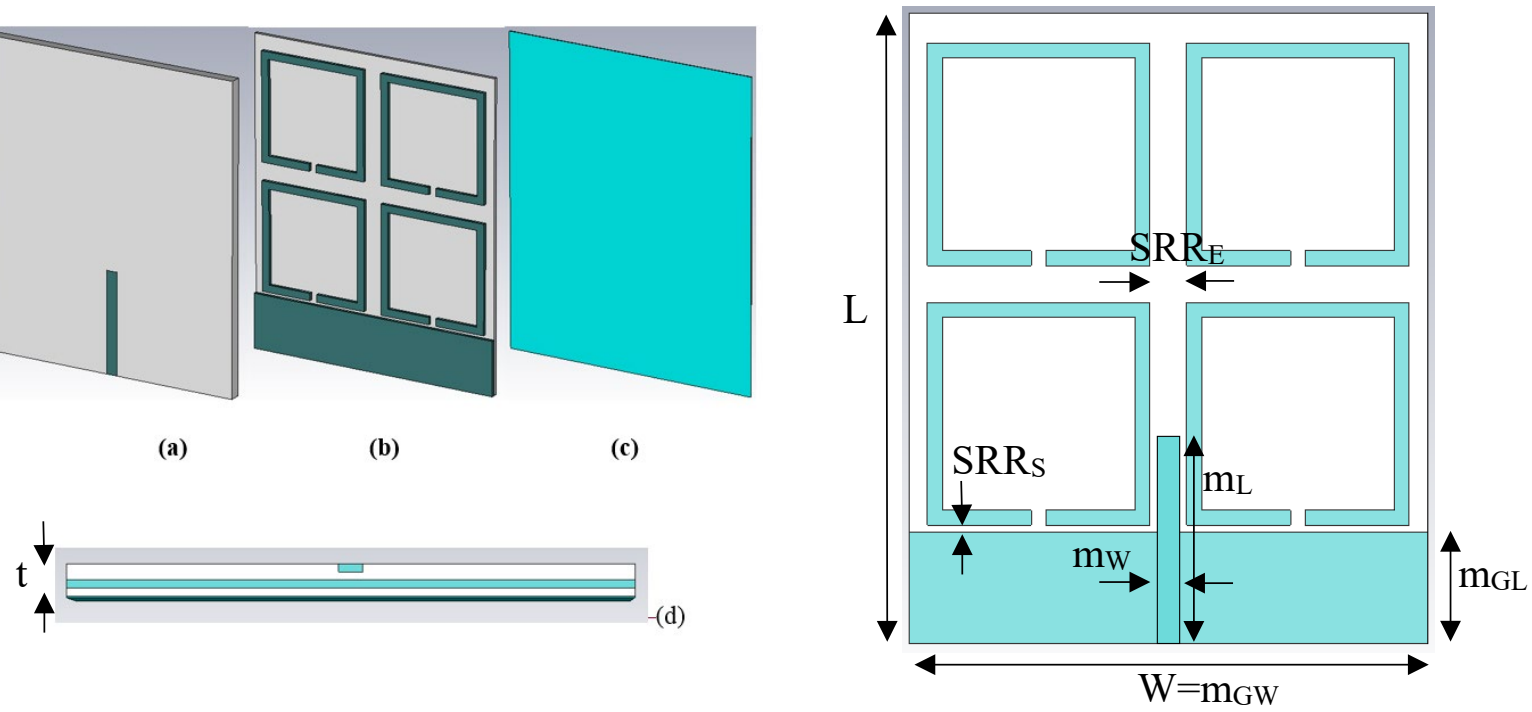

Figure 4. 3-felt layer metamaterial antenna. (a) Monopole layer. (b) EBG and monopole ground layer. (c) EBG ground layer. (d) Antenna cross section and geometrical parameters. 


\section{WILEY-VCH}

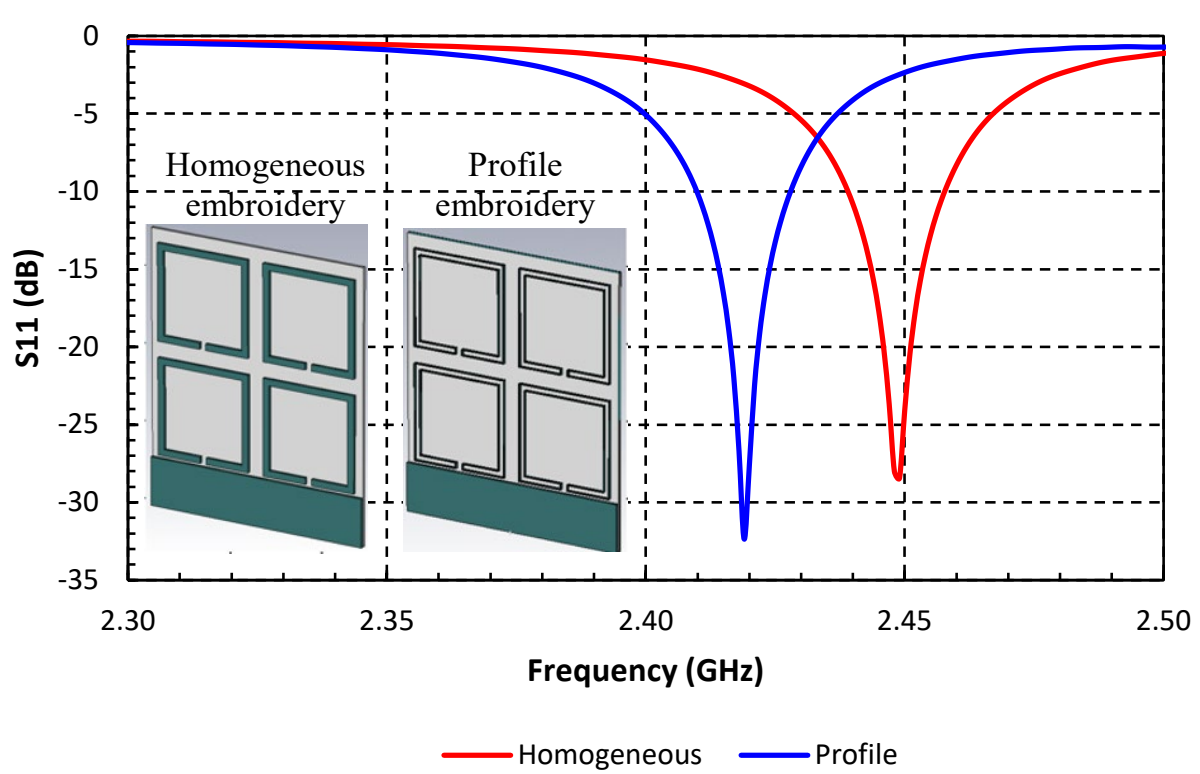

Figure 5. Metamaterial antenna return loss for homogeneous and profile embroidery pattern.

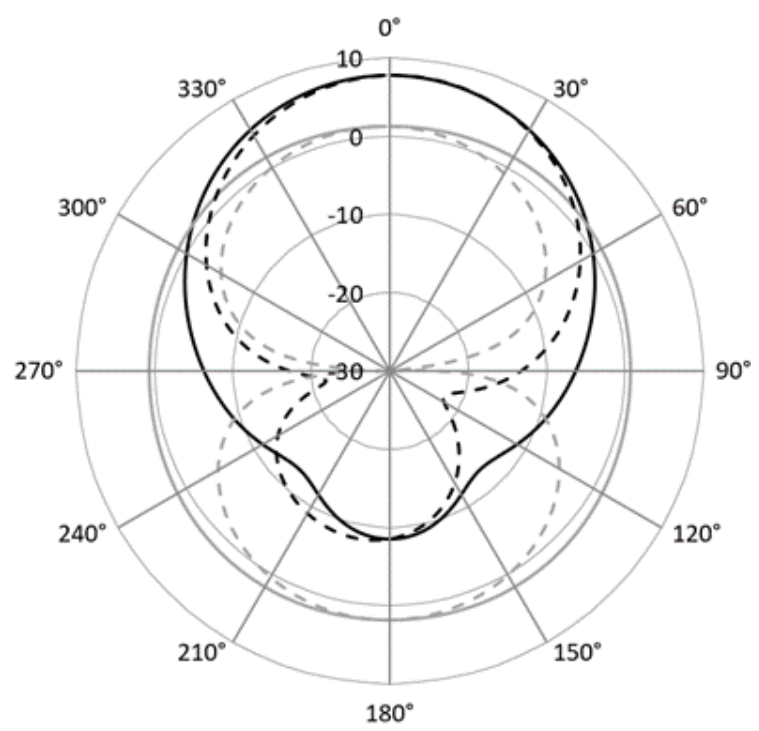

Figure 6. Radiation gain pattern at resonance frequency for the SRR metamaterial monopole felt antenna (black) and monopole (grey). Phi $=0^{\circ}$ (H-plane) is depicted with a solid line. $\mathrm{Phi}=90^{\circ}$ (E-plane) is depicted with a dashed line. 


\section{WILEY-VCH}

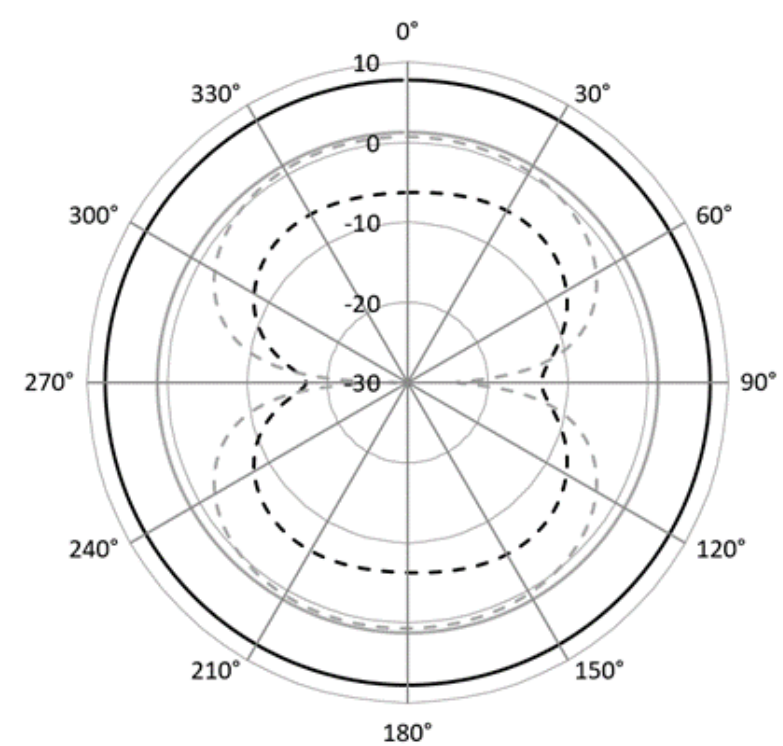

Figure 7. Radiation gain pattern at resonance frequency for the SRR metamaterial monopole felt antenna (black) and monopole (grey). Theta $=0^{\circ}$ (XY plane) is depicted with a solid line. Theta $=90^{\circ}$ (XY plane) is depicted with a dashed line.

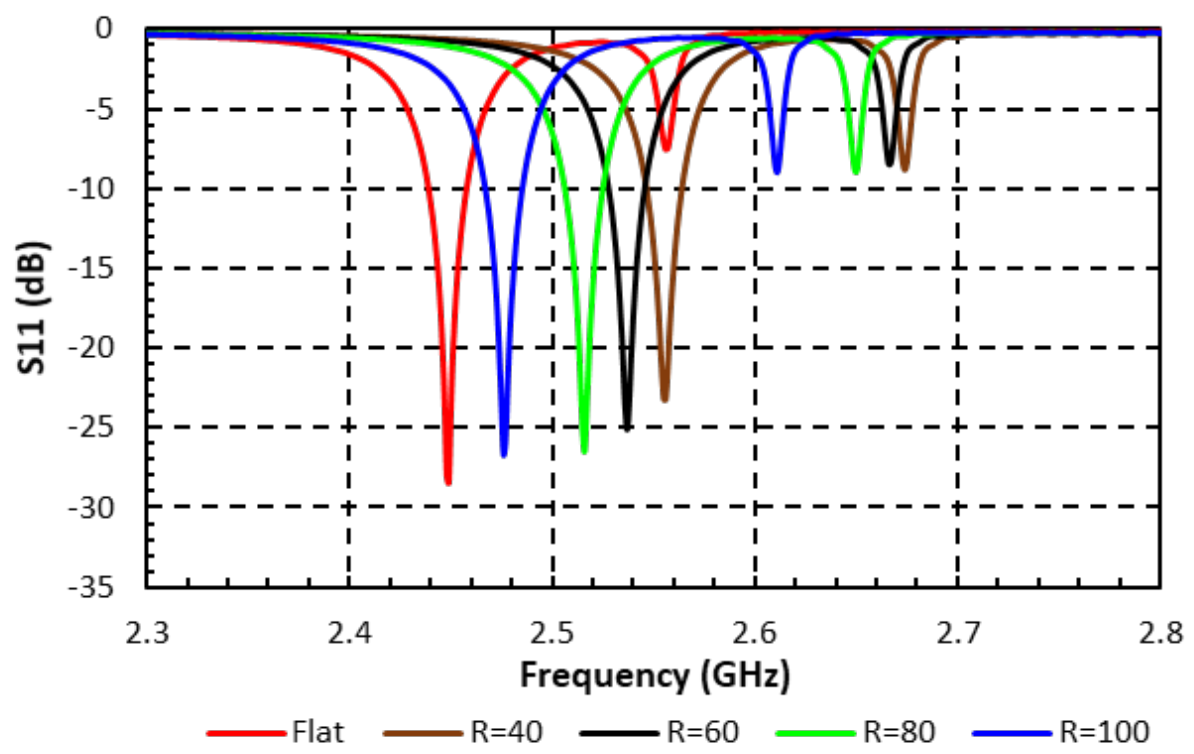

Figure 8. Metamaterial antenna return loss under bending effect. Radii units are given in mm. 


\section{WILEY-VCH}
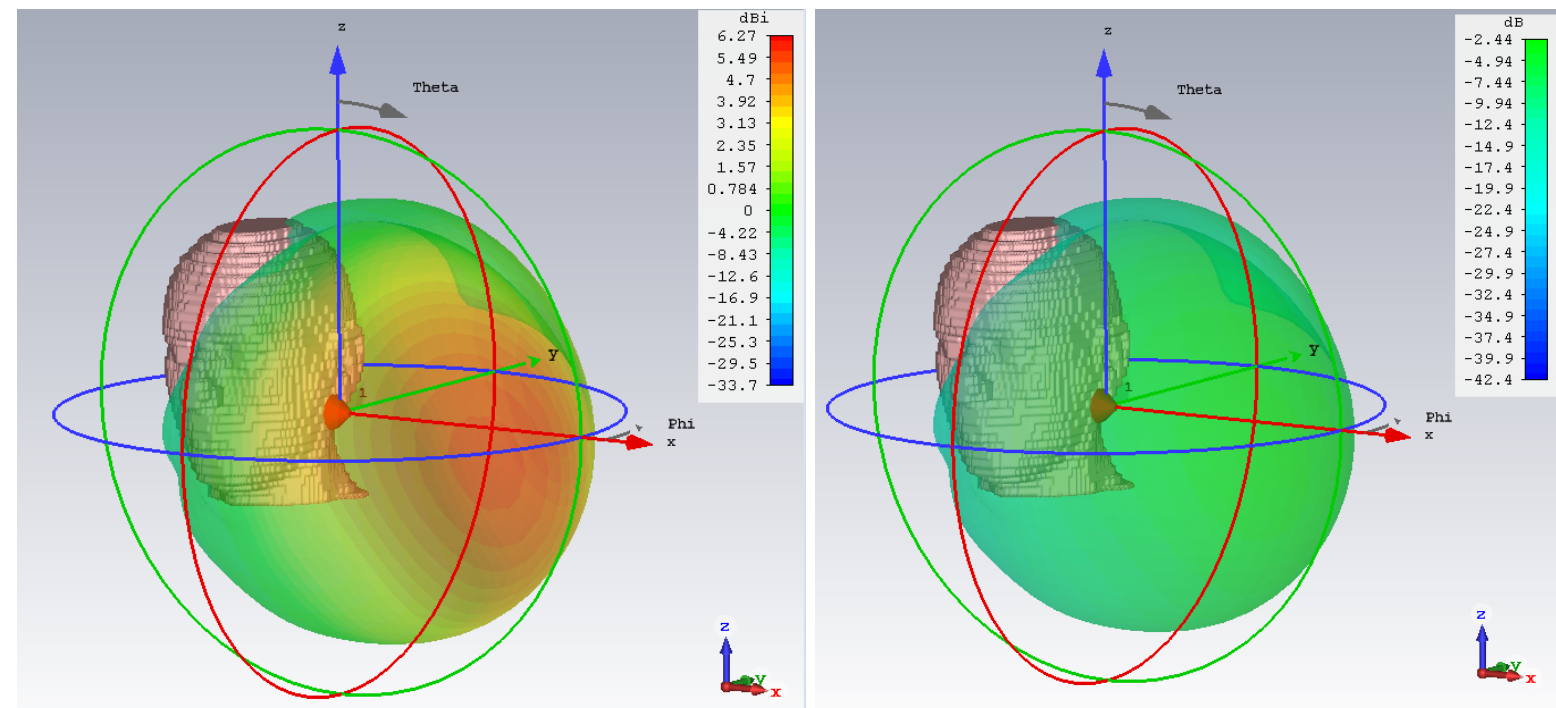

Figure 9. Simulation of the 3D Radiation pattern for the conventional monopole felt antenna located at the ear of the Gustav Model at $2.45 \mathrm{GHz}$. (a) Directivity. (b) Realized gain.
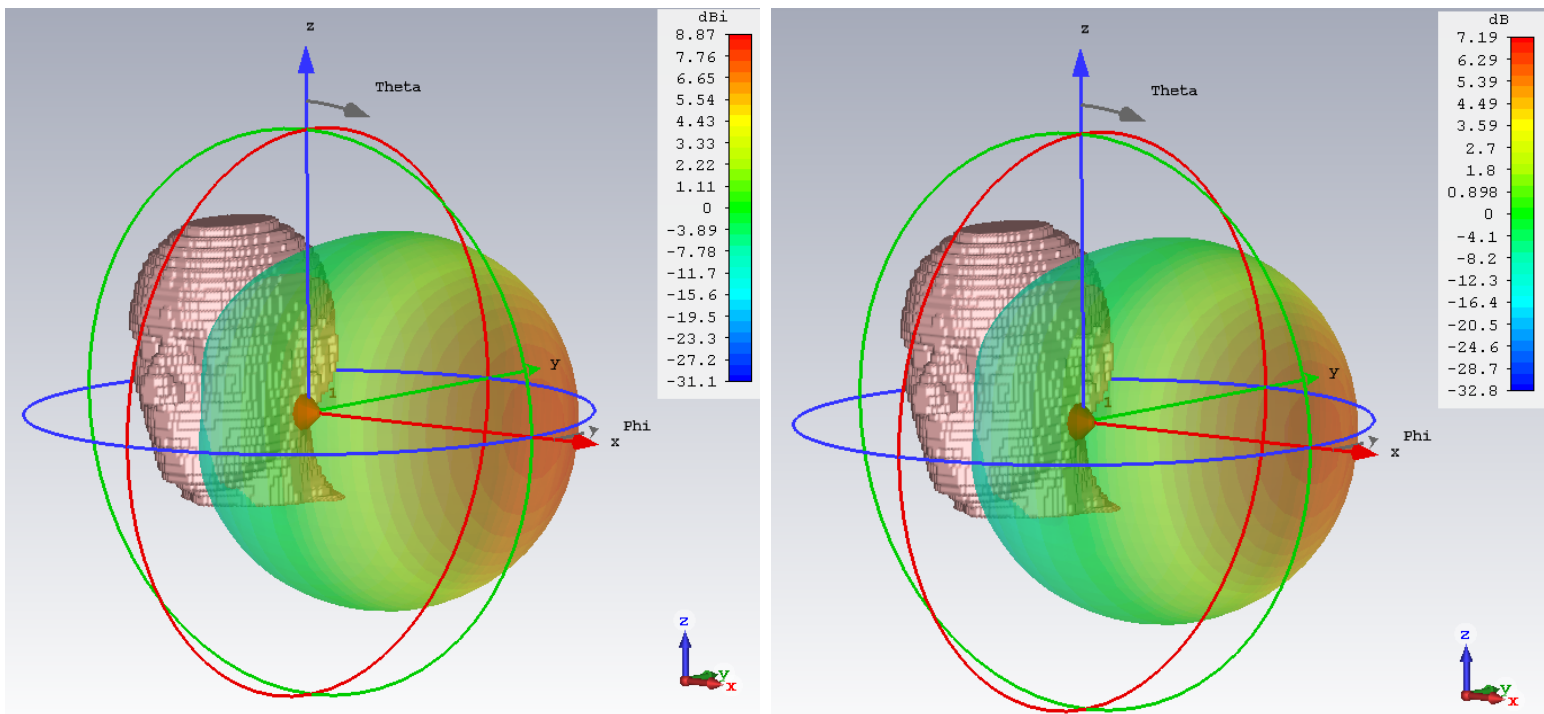

Figure 10. Simulation of the 3D Radiation pattern for the SRR metamaterial monopole felt antenna located at the ear of the Gustav Model at $2.41 \mathrm{GHz}$. (a) Directivity. (b) Realized gain. 


\section{WILEY-VCH}

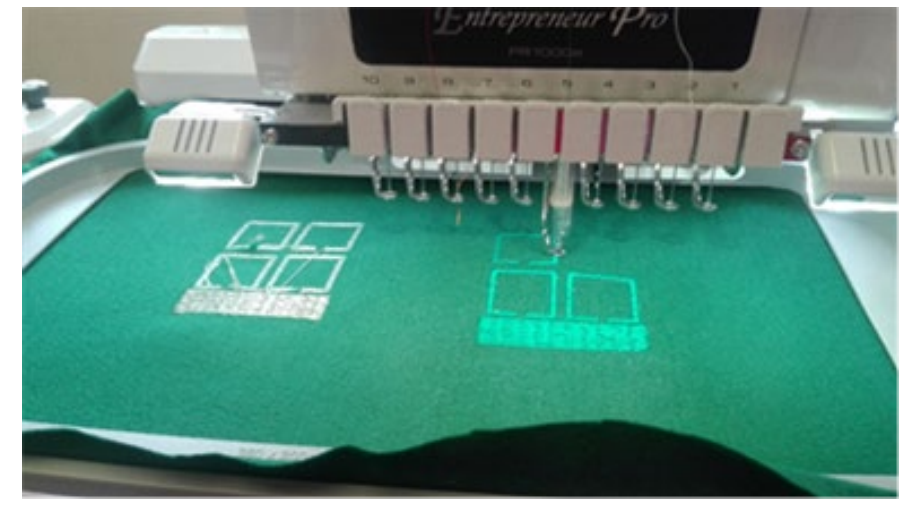

(a)
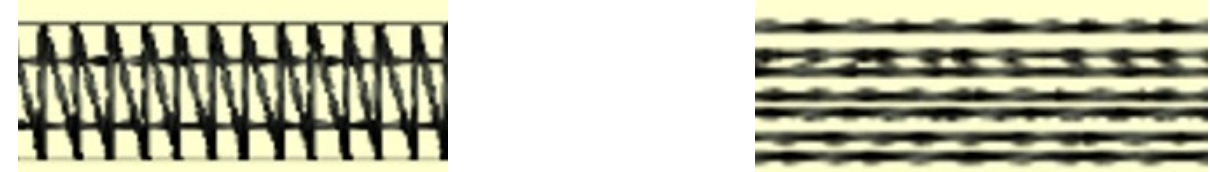

(b)

(c)

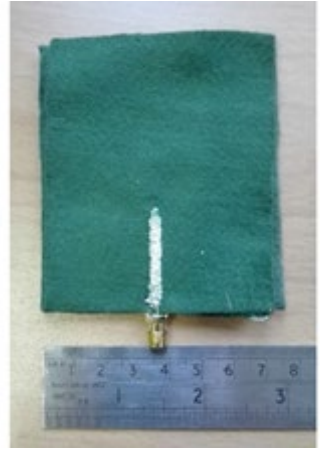

(d)

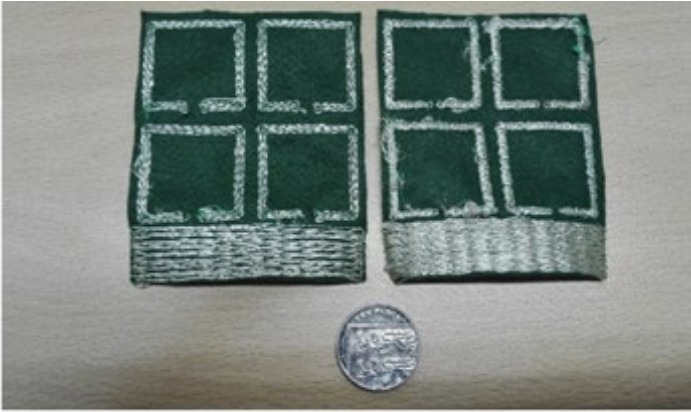

(e)

Figure 11. (a) Embroidery metamaterial antenna manufacturing process. (b) Satin fill stitch pattern embroidery layout. (c) Standard contour fill stitch pattern embroidery layout. Embroidered antennas: (d) Monopole. (e) EBG layer in several embroidery layout patterns. 


\section{WILEY-VCH}

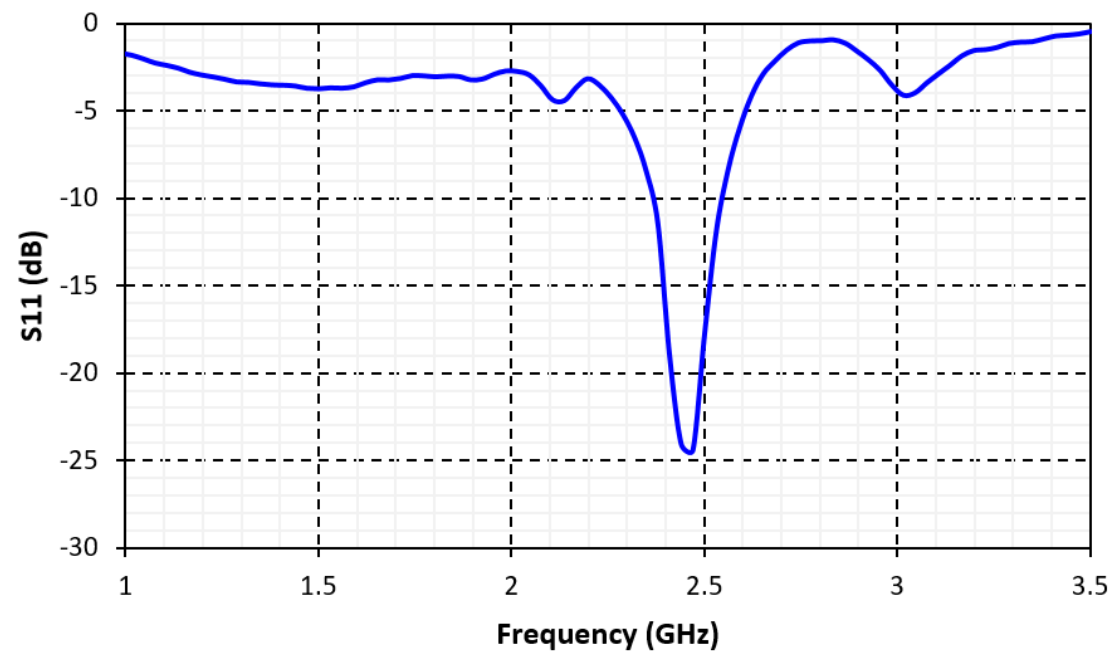

Figure 12. Metamaterial antenna return loss for homogeneous contour embroidery pattern.
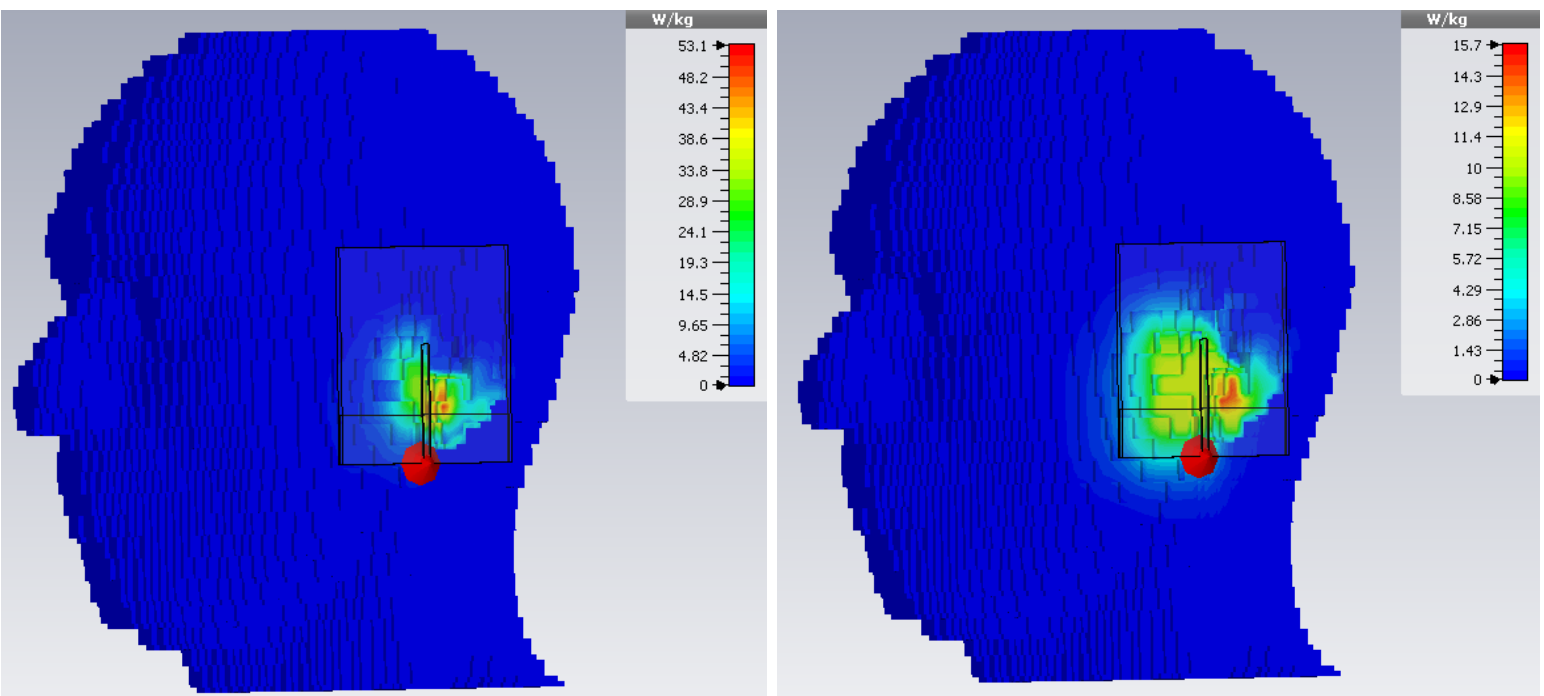

Figure 13. (a) SAR $1 \mathrm{~g}$ tissue and (b) SAR $10 \mathrm{~g}$ for the conventional monopole felt antenna located at the ear.
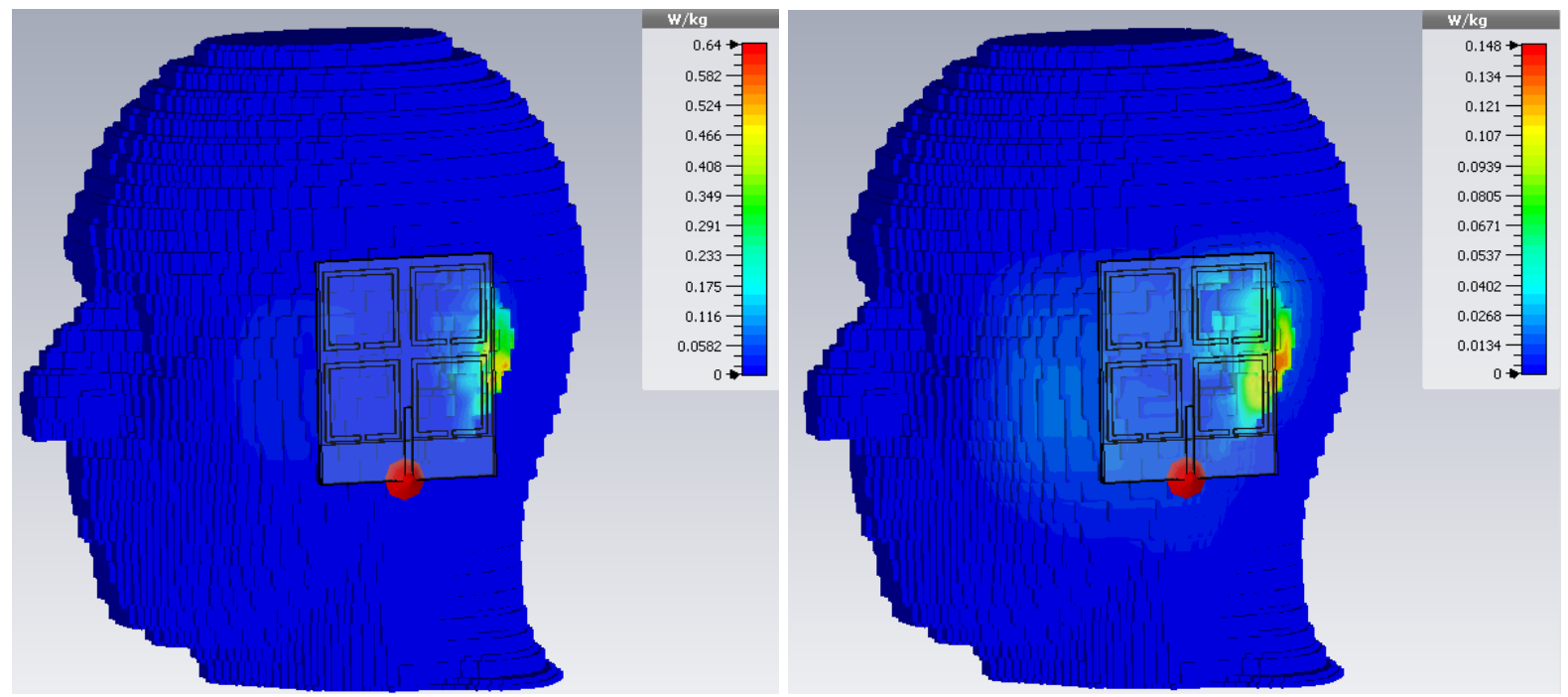
Figure 14. (a) SAR $1 \mathrm{~g}$ tissue and (b) SAR $10 \mathrm{~g}$ for the SRR metamaterial monopole felt antenna located at the ear.

$\underline{\text { Table 1. Textile antenna parameter summary at resonance frequency }}$

\begin{tabular}{lcccc}
$\begin{array}{l}\text { Textile } \\
\text { antenna }\end{array}$ & $\begin{array}{c}\text { Fcenter / S11 } \\
{[\mathrm{GHz} / \mathrm{dB}]}\end{array}$ & $\begin{array}{c}\text { Directivity } \\
{[\mathrm{dBi}]}\end{array}$ & $\begin{array}{c}\text { Gain } \\
{[\mathrm{dBi}]}\end{array}$ & $\begin{array}{c}\text { Efficiency } \\
(\%)\end{array}$ \\
\hline $\begin{array}{l}\text { Monopole } \\
\text { Free space }\end{array}$ & $2.45 /-14.8$ & 1.99 & 1.84 & 96.6 \\
$\begin{array}{l}\text { Monopole SRR } \\
\text { Homogeneous } \\
\text { Free space }\end{array}$ & $2.45 /-28.3$ & 8.76 & 7.81 & 80.4 \\
$\begin{array}{l}\text { Monopole SRR } \\
\begin{array}{l}\text { Profile } \\
\text { Free space }\end{array}\end{array}$ & $2.42 /-32.1$ & 8.68 & 7.69 & 79.6 \\
$\begin{array}{l}\text { Monopole } \\
\text { Voxel model }\end{array}$ & $2.56 /-15.0$ & 6.27 & -2.44 & 13.5 \\
$\begin{array}{l}\text { Monopole SRR } \\
\text { Homogeneous } \\
\text { Voxel model }\end{array}$ & $2.41 /-25.0$ & 8.87 & 7.19 & 67.9 \\
$\begin{array}{l}\text { Monopole SRR } \\
\text { Profile } \\
\text { Voxel model }\end{array}$ & $2.40 /-35.2$ & 9.06 & 7.52 & 70.1 \\
\hline
\end{tabular}

Table 2. Localized SAR (head and trunk) restrictions for public and occupational exposure

\begin{tabular}{lcc}
\hline & $\begin{array}{c}\text { Peak SAR 1g tissue } \\
{[\mathrm{W} / \mathrm{Kg}]}\end{array}$ & $\begin{array}{c}\text { Peak SAR 10g tissue } \\
{[\mathrm{W} / \mathrm{Kg}]}\end{array}$ \\
\hline Public & 1.6 & 2 \\
Occupational & 8 & 10 \\
\hline
\end{tabular}

Table 3. SAR values for the voxel model at resonance frequency @ pin=17 dbm and maximum allowed power to satisfy SAR standard

\begin{tabular}{lcccc}
\hline $\begin{array}{l}\text { Textile } \\
\text { antenna }\end{array}$ & $\begin{array}{c}\text { Peak SAR 1g tissue } \\
\text { [W/Kg] }\end{array}$ & $\begin{array}{c}\text { SAR 1g Max. Pin } \\
{[\mathrm{dBm}]}\end{array}$ & $\begin{array}{c}\text { Peak SAR 10g tissue } \\
{[\mathrm{W} / \mathrm{Kg}]}\end{array}$ & $\begin{array}{c}\text { SAR 10g Max. Pin } \\
{[\mathrm{dBm}]}\end{array}$ \\
\hline $\begin{array}{l}\text { Monopole } \\
\text { @2.56 GHz }\end{array}$ & 53.07 & - & 15.73 & - \\
$\begin{array}{l}\text { Monopole SRR } \\
\text { Homogeneous }\end{array}$ & 0.64 & & & \\
@2.41 GHz & & 21.0 & 0.148 & 28.3 \\
$\begin{array}{l}\text { Monopole SRR } \\
\begin{array}{l}\text { Profile } \\
\text { @2.40 GHz }\end{array}\end{array}$ & 0.48 & & & \\
\hline
\end{tabular}

